\title{
Contactless, non-intrusive core temperature measurement of a solid body in steady- state
}

\author{
Dean Anthony, Daipayan Sarkar, Ankur Jain* \\ Mechanical and Aerospace Engineering Department \\ University of Texas at Arlington, Arlington, TX, USA. \\ * - Corresponding Author: email: jaina@uta.edu; \\ 500 W First St, Rm 211, Arlington, TX, USA 76019 \\ Ph: +1 (817) 272-9338; Fax: +1 (817) 2722952
}

\section{Abstract}

Accurate measurement of temperature is critical for understanding thermal behavior and monitoring safety and performance of engineering systems involving heating and cooling. While a number of methods are available for measurement of temperature on the outside surface of solid bodies, there is a lack of contactless, non-invasive methods for determining temperature inside solid bodies. Development of such methods is likely to impact a wide range of engineering systems. This paper describes and validates a method for measurement of internal temperature of a solid body based on measurement of the temperature distribution on its outside surface. A theoretical model is developed for determining the core temperature of a cylinder based on surface temperature measurement. This method is validated by determining the core temperature of a thermal test cell using infrared temperature measurement on the surface, and comparing with measurements from an embedded thermocouple. The two measurements are found to agree well with each other in a variety of heat generation and cooling conditions. While this validation is presented for a cylindrical body, the method lends itself easily to bodies of other shapes. This work contributes towards fundamental thermal metrology, with possible applications in a wide variety of engineering systems. 
Keywords: Temperature Measurement; Internal Temperature' Infrared Thermography; Analytical Thermal Modeling.

\section{Introduction}

Temperature directly affects the performance, safety and reliability of a variety of engineering systems relevant for energy conversion. Most physical processes that occur in such systems are closely coupled to the temperature field. For example, in a Li-ion cell, electrochemical reactions during energy storage and conversion determine the temperature field in the cell [1-4], which, in turn, affects the rate of these electrochemical reactions [5]. Measurement of temperature is a critical step for ensuring safety, reliability and high performance of engineering systems involving heating and cooling, as well as for fully understanding coupled, multiphysics phenomena that occur in such systems. In general, temperature is measured based on a linear change in a measurable characteristic as a function of temperature [6-7]. This includes electrical resistance [8], thermal expansion [8], reflectance [9], circuit resonant frequency [10], color [11], surface radiation [12], etc. A variety of temperature measurement methods, varying in their accuracy and complexity have been used to measure transient and steady state temperature either at discrete locations, or over an entire surface.

While a number of methods are available for temperature measurement on the outside surface of a solid, there is a relative lack of methods for non-invasively measuring temperature inside solids. Internal temperature measurement is relatively more challenging, particularly when a remote, contactless method is desired, but is also very important, since the safety and performance of systems depends critically on the internal temperature, which for heat-generating 
bodies is typically higher than the outside surface temperature. One example to illustrate this is a nuclear fuel rod, which is usually cylindrical in nature and has relatively low thermal conductivity [13]. Heat generation within the fuel rod due to fission reactions results in a temperature field within the rod, with the core of the rod usually being much hotter than the outside [14-15]. While the outside temperature of the fuel rod can be measured using a variety of surface temperature measurement techniques, measuring the temperature in the core of the fuel rod is not straightforward. In this case, a remote, contactless method for internal temperature measurement that does not disrupt the function of the fuel rod is very desirable. Another example is a Li-ion cell commonly used for electrochemical energy conversion and storage $[1,16]$. In a Li-ion cell, electrochemical reactions and electrical impedance results in significant heat generation and temperature rise throughout the cell volume $[2,17]$. Due to the poor radial thermal conductivity of the Li-ion cell [18], a significant temperature gradient within the cell is known to exist $[17,19-20]$. Performance optimization and safety of the cell requires information about the peak temperature of the cell, which occurs in the core of the cell, and is difficult to measure [17] as the cell is hermetically sealed, and drilling a hole through the cell to insert a temperature sensor will short circuit and disrupt the electrochemical function of the cell. On the other hand, use of the surface temperature of the cell instead of core temperature is not appropriate, and may lead to severe under-design of the thermal management of the cell. These examples illustrate the need for and importance of contactless, non-intrusive measurement of the internal temperature of engineering systems. Such a measurement method will clearly be of universal appeal.

Internal measurement of a variety of physical quantities other than temperature such as stress, chemical composition, morphology, crystal structure, etc. is possible using various measurement methods [21-24]. For example, internal morphology and chemical composition can 
be measured using x-ray CT scans [24] that make use of the absorptivity of electromagnetic radiation by different materials. A variety of contactless, non-intrusive methods based on synchrotron x-ray, neutron scattering and ultrasonic waves also exist for internal stress measurement [25]. In comparison, however, there is a distinct lack of contactless, non-intrusive methods for measurement of temperature inside solid bodies. Most present methods provide information about either the surface temperature or the volumetrically averaged temperature, neither of which may be representative of the internal temperature of the solid. Only very limited work exists on measuring internal temperature of solids [26-29]. For example, the temperature dependence of speed of ultrasonic waves through a solid has been utilized to measure the average temperature along a path through the solid by measuring the time of flight of an ultrasonic wave along that path [28-29]. Measurements along multiple paths through the body have been used in conjunction with information about the nature of the temperature field, obtained from solving governing energy conservation equations, to reconstruct the temperature field [29]. Ultrasonic-based temperature measurement methods, however, do not work well for materials with high rates of ultrasonic attenuation, and may be cumbersome to implement. Internal temperature of a Li-ion cell has been measured through impedance spectroscopy, based on a relationship between the cell temperature and certain electrochemical parameters of the cell [30-32]. However, these methods are very specific to the electrochemical characteristics of this system and do not apply to a general heat-generating body.

This paper presents a contactless, non-intrusive method for measurement of the core temperature in a heat-generating solid body. A theoretical heat transfer model for a heatgenerating cylinder is developed to show that the core temperature of the cylinder can be measured using appropriate integrals of the measured spatial temperature distribution on the 
cylinder surface. Internal temperature measurement based on this approach is carried out for a thermal test cell in a variety of heat generation and convective conditions. These measurements are validated against a thermocouple embedded in the thermal test cell. The two are found to be in very good agreement. While this internal temperature measurement method is demonstrated here for a cylinder, a similar approach could be used for solids of other shapes. The next section presents theoretical models for non-intrusive determination of the core temperature based on surface temperature measurements. This is followed by a section describing the experimental test setup and methods. Results are presented and discussed next, followed by conclusions and future directions for this work.

\section{Mathematical Modeling}

Consider a heat generating cylinder for which measurement of internal temperature at $r=0$ is of interest, and for which temperature distribution on the outside surface is measured. This section presents the derivation of the temperature distribution within the cylinder, from where it is shown that the core temperature of the cylinder can be determined using the surface temperature distribution. Thermal conduction in the cylinder is assumed to be orthotropic, as is the case in several systems of engineering interest [18]. An infinite cylinder is considered in section 2.1, and extension to a cylinder of finite length is discussed in section 2.2.

\subsection{Infinite Cylinder}

Figure 1(a) shows a schematic of the general heat transfer problem analyzed in this section. Consider an infinitely long cylinder of radius $R$, with volumetric internal heat generation at a rate of $Q$. The radial and circumferential thermal conductivities are $k_{r}$ and $k_{\theta}$ respectively. Assume that the temperature distribution along the outer surface at $r=R$ is measured to be a function of $\theta$, 
given by $T_{0}(\theta)$. In steady state, the energy conservation equation that governs the temperature field in the cylinder is given by

$$
\left(\frac{\partial^{2} T}{\partial r^{2}}+\frac{1}{r} \frac{\partial T}{\partial r}\right)+\frac{k_{\theta}}{k_{r}}\left(\frac{1}{r^{2}} \frac{\partial^{2} T}{\partial \theta^{2}}\right)+\frac{Q}{k_{r}}=0
$$

where $T(r, \theta)$ is the temperature rise above ambient. The temperature distribution within the cylinder is subject to the following boundary conditions:

$$
\begin{gathered}
\left.\frac{\partial T}{\partial r}\right|_{r=0}=0 \\
T(R, \theta)=T_{0}(\theta) \\
T(r, \theta)=T(r, \theta+2 \pi) \\
\left.\frac{\partial T}{\partial \theta}\right|_{\theta}=\left.\frac{\partial T}{\partial \theta}\right|_{\theta+2 \pi}
\end{gathered}
$$

Equation (2) represents the requirement for the temperature field to be finite at $r=0$. Equation (3) accounts for the measured temperature distribution $T_{0}$ on the outside surface of the cylinder. Note that if the extent of convective cooling varies significantly around the cylinder, as it does for forced convective cooling, $T_{0}$ will be a function of $\theta$. Equations (4) and (5) represent periodicity in temperature and heat flux in the circumferential direction. 
In order to determine the core temperature $T_{\text {core }}$ at $r=0$ in terms of the measured temperature distribution $T_{0}(\theta)$, a solution for the general temperature field $T(r, \theta)$ must be derived. To do so, the temperature field is first transformed as follows,

$$
T(r, \theta)=w(r, \theta)+\frac{Q\left(R^{2}-r^{2}\right)}{4 k_{r}}
$$

This results into a homogeneous governing equation for $w(r, \theta)$ as follows:

$$
k_{r}\left(\frac{\partial^{2} w}{\partial r^{2}}+\frac{1}{r} \frac{\partial w}{\partial r}\right)+\frac{k_{\theta}}{k_{r}}\left(\frac{1}{r^{2}} \frac{\partial^{2} w}{\partial \theta^{2}}\right)=0
$$

subject to

$$
\begin{gathered}
\left.\frac{\partial w}{\partial r}\right|_{r=0}=0 \\
w(R, \theta)=T_{0}(\theta) \\
w(r, \theta)=w(r, \theta+2 \pi) \\
\left.\frac{\partial w}{\partial \theta}\right|_{\theta}=\left.\frac{\partial w}{\partial \theta}\right|_{\theta+2 \pi}
\end{gathered}
$$

A solution for $w(r, \theta)$ can be expressed as follows 


$$
w(r, \theta)=C_{0}+\sum_{m=1}^{\infty} C_{m} \cos (m \theta)\left(\frac{r}{R}\right)^{m \sqrt{k_{\theta} / k_{r}}}
$$

This form for $w(r, \theta)$ satisfies the governing equation (7) and all boundary conditions except the one at $r=R$ expressed in equation (9). The coefficients $C_{0}$ and $C_{m}$ in this solution must be chosen in order to ensure that equation (9) is also satisfied.

Note that the core temperature $T_{\text {core }}$ is obtained by substituting $r=0$ in equations (6) and (12), resulting in

$$
T_{\text {core }}=T(r=0, \theta)=C_{0}+\frac{Q R^{2}}{4 k_{r}}
$$

This shows that the core temperature can be determined only in terms of the first coefficient $C_{0}$, and that no further coefficients are needed. To determine $C_{0}$, equation (12) is inserted in equation (9) to get

$$
C_{0}+\sum_{m=0}^{\infty} C_{m} \cos (m \theta)=T_{0}(\theta)
$$

Finally, integrating Eq. (14) with respect to $\theta$ between 0 and $2 \pi$ eliminates all coefficients except $C_{0}$, resulting in

$$
C_{0}=\frac{1}{2 \pi} \int_{0}^{2 \pi} T_{0}(\theta) d \theta
$$

From equations (13) and (15), the core temperature may be expressed in terms of the measured outside surface temperature $T_{0}(\theta)$ as follows 


$$
T_{\text {core }}=\frac{1}{2 \pi} \int_{0}^{2 \pi} T_{0}(\theta) d \theta+\frac{Q R^{2}}{4 k_{r}}
$$

Equation (16) shows the core temperature of the cylinder can be obtained from the circumferential integral of the measured outside temperature. Note that this measurement approach requires information about the volumetric heat generation rate, which may be known a priori based on the physical mechanism responsible for heat generation, as well as the radial thermal conductivity $k_{r}$, which may be known based on the material of the cylinder. The circumferential thermal conductivity $k_{\theta}$ is not needed for measurement of $T_{\text {core }}$ even if thermal conduction in the cylinder may be orthotropic.

\subsection{Finite Cylinder}

This section extends the model presented in section 2.1 to a finite cylinder of length $\mathrm{L}$, and shows how the core temperature $T_{\text {core }}(z)$ may be determined from measurement of the outside surface temperature, $T_{0}(\theta, z)$. Note the $z$ variation in both $T_{\text {core }}$ and $T_{0}$ due to the finite length of the cylinder. The geometry considered in this section is shown schematically in Figure 1(b). It is assumed that the two axial ends of the cylinder are convectively cooled with a heat transfer coefficient $h$. Under these assumptions, the steady state governing equation for the temperature field $T(r, \theta, z)$ is given by

$$
\left(\frac{\partial^{2} T}{\partial r^{2}}+\frac{1}{r} \frac{\partial T}{\partial r}\right)+\frac{k_{\theta}}{k_{r}}\left(\frac{1}{r^{2}} \frac{\partial^{2} T}{\partial \theta^{2}}\right)+\frac{k_{z}}{k_{r}} \frac{\partial^{2} T}{\partial z^{2}}+\frac{Q}{k_{r}}=0
$$

Similar to the infinite cylinder case, the temperature field satisfies boundary conditions given by equations (2), (4) and (5). In addition, the following boundary conditions also apply: 


$$
\begin{array}{ll}
T(R, \theta, z)=T_{0}(\theta, z) & \text { at } \mathrm{z}=0 \\
k \frac{d T}{d z}=h T & \text { at } \mathrm{z}=\mathrm{L} \\
k \frac{d T}{d z}=-h T &
\end{array}
$$

A general solution for this partial differential equation is given by [33]

$$
T(r, \theta, z)=\frac{Q L^{2}}{2 k_{z}}\left[\frac{z}{L}\left(1-\frac{z}{L}\right)+\frac{1}{B i}\right]+\sum_{m=0}^{\infty} \sum_{n=1}^{\infty} C_{m, n} I \underset{m \sqrt{\frac{k_{\theta}}{k_{r}}}}{ }\left(\eta_{n} \sqrt{\frac{k_{z}}{k_{r}}} r\right) \cos (m \theta)\left[\frac{h}{\eta_{n} k_{z}} \sin \left(\eta_{n} z\right)+\cos \left(\eta_{n} z\right)\right]
$$

where $I$ is the modified Bessel function of the first kind, and $B i=\frac{h \cdot L}{k_{z}}$. The eigenvalues $\eta_{n}$ are determined from roots of the equation

$$
\tan \left(\eta_{n} L\right)=\frac{2\left(\eta_{n} \cdot L\right) B i}{\left(\eta_{n} \cdot L\right)^{2}-B i^{2}}
$$

From equation (21), the core temperature $T_{\text {core }}(z)$ is given by

$$
T_{\text {core }}(z)=T(r=0, \theta, z)=\frac{Q L^{2}}{2 k_{z}}\left[\frac{z}{L}\left(1-\frac{z}{L}\right)+\frac{1}{B i}\right]+\sum_{n=1}^{\infty} C_{0, n}\left[\frac{h}{\eta_{n} k_{z}} \sin \left(\eta_{n} z\right)+\cos \left(\eta_{n} z\right)\right]
$$

Note that setting $r=0$ in equation (21) eliminates all terms with coefficients $C_{m, n}$, where $m>0$, in the expression for $T_{\text {core }}(z)$. Thus, measurement of $T_{\text {core }}(z)$ requires only $C_{0, n}$ coefficients. To determine these coefficients, equation (21) is inserted in equation (18), followed by 
multiplication with $\left[\frac{h}{\eta_{j} k_{z}} \sin \left(\eta_{j} z\right)+\cos \left(\eta_{j} z\right)\right]$, and integration in $z$ and $\theta$. Using the principle of orthogonality for the eigenvalues in the $z$ and $\theta$ directions, this results in

$$
C_{0, j}=\frac{-\frac{Q L^{2}}{2 k_{z}} F_{j}+\frac{1}{2 \pi} \int_{0}^{2 \pi L} \int_{0} T_{0}(\theta, z)\left(\frac{h}{\eta_{j} k_{z}} \sin \left(\eta_{j} z\right)+\cos \left(\eta_{j} z\right)\right) d z d \theta}{N_{j} \cdot I_{0}\left(\eta_{j} \sqrt{\frac{k_{z}}{k_{r}}} R\right)}
$$

where $F_{j}$ is given by

$$
F_{j}=\int_{0}^{L}\left(\frac{z}{L} \cdot\left(1-\frac{z}{L}\right)+\frac{1}{B i}\right) \cdot\left(\frac{h}{\eta_{j} k_{z}} \sin \left(\eta_{j} z\right)+\cos \left(\eta_{j} z\right)\right) d z
$$

and the norm $N_{j}$ is given by [34]

$$
N_{j}=\left(\frac{h^{2}}{\left(\eta_{j} k_{z}\right)}+1\right) \frac{L}{2}+\frac{h}{k_{z} \eta_{j}^{2}}
$$

Equations (23)-(26) provide an analytical expression for the core temperature $T_{\text {core }}(z)$ in terms of appropriate circumferential and axial integrals of the measured outside temperature distribution $T_{0}(\theta, z)$.

Note that, in comparison to the infinite cylinder case, the axial thermal conductivity $k_{z}$ is required for determining $T_{\text {core }}(z)$, since thermal conduction in the axial direction occurs in the finite cylinder.

The theoretical derivations in sections 2.1 and 2.2 provide a contactless, non-intrusive method for measuring the core temperature at $r=0$ for infinite and finite cylinders respectively. 
The theoretical treatment shows that these temperatures can be obtained using appropriate integrals of the measured temperature distribution on the outside surface of the cylinder. While this discussion is specific to a cylinder, this approach could also be used for a body of any shape, provided one is able to solve the thermal conduction problem within the body, similar to the approach presented here for a cylinder. The solution of the thermal conduction problem for a body of a given shape provides the relationship between the core and outside temperatures, similar to equations (16) and (23).

The next section discusses experiments carried out to validate this core temperature measurement approach using a thermal test cell.

\section{Experiments}

Experiments are carried out to validate the method described in section 2 to measure the core temperature of a cylinder using outside surface temperature measurements. This section describes components of the experimental setup, as well as the experimental procedure for validation.

\subsection{Thermal Test Cell}

A cylindrical thermal test cell capable of volumetric heat generation through Joule heating is designed and fabricated for these experiments. A picture and a schematic diagram of the thermal test cell are shown in Figures 2(a) and 2(b) respectively. Thin metal foil of thickness $0.025 \mathrm{~mm}$ is first insulated by adhering Kapton tape on its surface. The foil-Kapton sandwich is rolled around a thin rod to form a cylinder of height $65 \mathrm{~mm}$ and radius $13 \mathrm{~mm}$. A T-type thermocouple is placed at the inner core during this rolling process. Thin metal wires are soldered to the two ends of the metal foil to provide electrical access to the metal foil. The roll is then lowered inside a hollow Aluminum casing. Electrical current through the metal foil inside 
the roll provides volumetric heating throughout the test cell. The lead wires are routed out of the casing along with the thermocouple wire. Remaining volume inside the casing is filled with uncured poly-dimethylsiloxane, a commonly used electrically insulating soft polymer, followed by curing at room temperature. A dessicator is used to remove most air bubbles from the mixture of PDMS and curing agent prior to pouring. The long cure time ensures removal of any remaining air bubbles. PDMS filling is carried out in two steps in order to expel all air inside the test cell. Once filled with PDMS and cured, the test cell is sealed with an epoxy. Lead wires coming out of the test cell provide the capability of passing a heating current through the metal foil, as well as measuring the temperature of the thermocouple embedded in the core of the cell. The thermocouple measurements facilitate validation of core temperature measurement method described in section 2. Note the black color of the outer surface of the test cell in Figure 2(a) due to application of a graphite film to facilitate infrared (IR) temperature measurement.

\subsection{Measurement of Radial Thermal Conductivity of Thermal Test Cell}

As shown in equation (16), the radial thermal conductivity $k_{r}$ is needed for determining the core temperature of the thermal test cell. Experiments are carried out to measure $k_{r}$, based on the temperature response due to adiabatic heating of the test cell at the outer radial surface [18]. This method has been described in detail in a recent paper [18]. A T-type thermocouple is first attached to the outer surface of the cell at mid-height $(\mathrm{r}=\mathrm{R}, \mathrm{z}=\mathrm{H} / 2)$. A thermal epoxy is used for improving thermal contact between the cylinder surface and the thermocouple bead. A flexible Kapton heater is then wrapped around the test cell to provide radial heatingThe entire test cell is then insulated using fiberglass insulation tape, and placed in a vacuum ambient (-75 $\mathrm{kPa}$ (gage)) to minimize unaccounted heat loss from the test cell. The cell is suspended on thin paper arms to minimize thermal conduction loss through surface area contact. It has been shown [18] that in 
this case, the temperature distribution at the outer surface is given by

$$
\theta(R, t)=\frac{2 Q^{\prime \prime}}{\rho C_{p} R} t+\frac{Q^{\prime \prime} R}{4 k_{r}}-\frac{2 Q^{\prime \prime} R}{k_{r}} \sum_{n=1}^{\infty} \frac{1}{\left(\lambda_{n} R\right)^{2}} \exp \left(-\frac{k_{r} \lambda_{n}^{2}}{\rho C_{p}} t\right)
$$

where $Q^{\prime \prime}$ is the applied heat flux, and eigenvalues $\lambda_{n}$ are obtained from roots of the equation $J_{0}^{\prime}\left(\lambda_{n} R\right)=0 . J_{0}$ denotes Bessel function of the first kind of order 0. As a result, the radial thermal conductivity $k_{r}$ may be determined by comparing the intercept of temperature measured by the thermocouple as a function of time, with the second term in equation (27). For this experiment, electric current is provided by a Keithley 2612A power supply, potential difference is measured by a Keithley 2100 digital multimeter, and thermocouple measurements are carried out through NI-9213 thermocouple module and LabView data acquisition software. Note that this experiment is separate from the main, core temperature measurement experiment, and is carried out only for radial thermal conductivity measurement.

\subsection{Experimental setup for temperature measurement}

Figure 3(a) shows a picture of the experimental setup for core temperature measurement. Figure 3(b) shows a block diagram representing the data acquisition process and various instruments used in the experiment. A FLIR A6703sc InSb infrared camera is mounted above an optical breadboard. The thermal test cell is placed directly under the camera, and is mounted on two thin, foam risers to minimize thermal conduction from the cell to the breadboard. In order to improve the accuracy of infrared temperature measurement, the outer surface of the thermal test cell is coated with a thin graphite film using a DGF-123 graphite aerosol spray. The resistive metal foil in the thermal test cell is connected to a GW INSTEK GPD-4303S power supply for supplying the heating current. Two additional probe wires monitor the potential difference across 
the test cell using a Keithley 2100 digital multimeter in order to monitor the heat generation rate. A small computer fan, Fugetek HT-07530D12, is placed approximately $10 \mathrm{~cm}$ away from the test cell at the same height as the cell axis, so that air from the fan directly impinges upon the outer surface of the test cell. The fan speed can be controlled using a power controller. A vane anemometer is used to measure the air speed. Data acquisition from the IR camera is carried out through an ethernet cord using ResearchIR software. LabView software is used for data acquisition from the thermocouple through a NI-9213 thermocouple module.

\subsection{IR Camera Calibration}

Accuracy of infrared-based temperature measurement depends critically on the quality of calibration carried out. In these experiments, the infrared camera is calibrated on an Instec HCS662V thermal stage, which can be set to any desired temperature between $-190{ }^{\circ} \mathrm{C}$ and 600 ${ }^{\circ} \mathrm{C}$. In this case, the temperature range of interest is room temperature to $80{ }^{\circ} \mathrm{C}$. The thermal stage is placed on the optical breadboard, directly under the infrared camera, as shown in the inset of Figure 4. Since infrared temperature measurement requires a highly emissive surface, two regions of the metal surface of Instec stage are covered with materials of high emissivity - a black tape and graphite film. The Instec stage is set to a number of temperatures between room temperature and $80^{\circ} \mathrm{C}$. At each set point, the stage temperature is allowed to reach steady state, and measured through the infrared camera. These measurements are carried without and with specifying emissivity and distance between sample and camera to investigate the effect of these calibration parameters on temperature measurement accuracy.

\subsection{Experiments}

Once the experiment is set up as described in section 3.3, temperature measurements are carried out on the thermal test cell in a number of conditions. For each case, a heating current is 
passed for Joule heating. Infrared surface temperature data are taken until the temperature distribution reaches steady state, which is also confirmed through measurement of the core temperature from the embedded thermocouple. The resistance of the test cell is measured in advance using a small test current that minimizes self-heating, and it is confirmed that the resistance does not increase appreciably due to temperature rise during the experiments.

For accurate extraction of surface temperature measurement, a region of interest is built into the measured temperature field from the infrared camera, and temperature across the outer surface at mid-height is extracted. In order to verify that the curved nature of the cylinder surface does not affect temperature measurement accuracy, experiments are carried out to measure temperature around the cylinder in isothermal conditions. A uniform temperature is measured around the cylinder, indicating that cylinder curvature does not affect IR measurement accuracy. Due to the curved surface of the cylinder, the $x$ coordinate across the cylinder's projected view as seen by the infrared camera is converted to the circumferential angle $\theta$. The axial dependence of temperature is also measured and examined to determine whether there is significant axial thermal conduction, which indicates whether the infinite or finite cylinder model is appropriate for data analysis.

Three sets of experiments are carried out. First, the steady-state surface temperature distribution on the test cell is measured at a number of heating powers while the cell is cooled in natural convection conditions. Subsequently, these experiments are repeated in the presence of forced convection cooling from the fan operating at a speed of around $3.0 \mathrm{~m} / \mathrm{s}$. Finally, a set of experiments is carried out at constant heating power, but with different fan speeds. In these experiments, the heating powers based on Joule heating in the metal foil are chosen in order to match the heating powers expected in Li-ion cells operating at high discharge rates [17]. In each 
experiment involving air flow from the fan, the flow field is allowed to stabilize for around ten minutes before the heating current is switched on. Sufficient cooling down time is provided between successive experiments to ensure that the cell reaches room temperature before the next experiment. In each experiment, the core temperature of the cell is determined using the theoretical model presented in section 2.1 and the experimentally measured surface temperature distribution. These core temperature measurements are compared against measurements from the embedded thermocouple to validate the measurement method.

\section{Results and discussion}

\subsection{Calibration of the IR Camera}

An HCS622V Instec thermal stage is used for IR camera calibration. Temperature of the stage is measured by the IR camera at a number of set temperatures. Figure 4 summarizes results from this experiment by plotting the measured temperature as a function of set temperature. The ideal $45^{\circ}$ line is shown, along which the measurement agrees exactly with the set temperature. Four calibration conditions are investigated. The stage temperature is measured with a black tape affixed on the stage, or with a thin film of graphite applied uniformly with a spray in order to improve surface emissivity. In each case, measurements are taken without and with specifying emissivity of the tape or spray, as well as the distance between the sample and camera. Figure 4 shows that there is some deviation between set and measured temperatures when emissivity and distance are not specified, for both black tape and graphite film. When these parameters are specified, the IR camera is able to measure surface temperature very accurately, as seen in Figure 4 where data for these cases are very close to the ideal $45^{\circ}$ line. The peak deviation between the stage temperature and IR-based temperature using graphite film is $0.92{ }^{\circ} \mathrm{C}$. While both black tape and graphite film work equally well, only graphite film is used in subsequent experiments, 
since it is less invasive in terms of affecting the surface properties of the sample, such as roughness, topography and insulation. It is also found that measurement accuracy is a weak function of specified distance between camera and sample, whereas when surface emissivity is not specified, the IR camera uses a default value, resulting in significant measurement error.

\subsection{Measurement of thermal conductivity of the test cell}

Supplementary Figure 1 plots the temperature rise measured by a thermocouple affixed on the outer surface of the thermal test cell during radial thermal conductivity measurements described in section 3.2. Experimental data agree well with the theoretical model, and the measured temperature profile increasing linearly with time after the initial transient period as expected. The intercept of this line is used to determine the radial thermal conductivity of the test cell, resulting in a value of $k_{r}=0.25 \mathrm{~W} / \mathrm{m}-\mathrm{K}$, which is close to the radial thermal conductivity of a 26650 Li-ion cell [18]. This value lies between the thermal conductivities of constituent materials, with PDMS and Kapton tape having very low, and the metal foil having very high thermal conductivity. Since the overall thermal conductivity of the test cell is based on a series combination of thermal resistances of constituent materials, the measured value of thermal conductivity of the test cell is along expected lines.

\subsection{Temperature measurement in natural convection conditions}

Once the IR camera is calibrated, and radial thermal conductivity of the thermal test cell is measured, experiments are carried out to non-invasively determine the core temperature of the thermal test cell through measurements of the outside temperature distribution using the IR camera. These experiments are carried out at different heat generation rates within the test cell, controlled by the amount of electric current passing through, and at different convective cooling 
conditions, controlled by the speed of the cooling fan which impinges air cross-flow on the cylinder. In each experiment, the core temperature determined from the theoretical model for an infinite cylinder in section 2 is compared with measurement from the thermocouple embedded in the core of the cell. Data presented later confirm that this is an appropriate model to use.

In the first set of experiments, the cooling fan is not on, so that there is no cross flow, and the test cell cools down through free convection. Figure 5 plots the experimentally measured core temperature, determined using the infinite cylinder model in section 2.2, against the thermocouple temperature measurement for a number of heating powers. The ideal $45^{\circ}$ line, along which the two are equal, is also shown. Figure 5 shows that in each case, the core temperature determined from the theoretical model using measurement of the outside temperature distribution is in close agreement with thermocouple measurements. The maximum error in these measurements is $0.63{ }^{\circ} \mathrm{C}$, which is well within the measurement errors associated with the IR camera and T-type thermocouple. These data demonstrate the capability of the theoretical model to determine the core temperature in a contactless, non-invasive fashion.

The circumferential distribution of measured temperature on the outside surface of the test cell for $2.2 \mathrm{~W}$ heating power is shown in Figure 6, which also plots this distribution for a case of forced convective cooling at the same power. Note that for better visualization, data in this plot are non-dimensionalized based on peak temperature measurement for each cooling condition. It is seen that there is some circumferential variation in the outside temperature measurement for the first set of experiments, but the variation is much greater in the forced convective case. This is along expected lines, as the imposition of a crossflow produces circumferential variation in local convective heat transfer [35], resulting in a circumferentially 
varying temperature distribution in the cylinder [33]. In addition, there is greater measurement noise in the forced convection case due to imposition of crossflow over the test cell.

\subsection{Temperature measurement in forced convection conditions}

Experiments described in Section 4.3 are repeated in the presence of cross-flow of air from a fan located around $10 \mathrm{~cm}$ from the test cell. Figure 7 plots the circumferential variation in the measured outside temperature for a number of heating powers at fixed fan speed. Temperature curves shift upwards with increasing power, as expected, while the nature of the circumferential variation remains the same. In each case, the measured temperature distribution is integrated to determine the core temperature, as shown in section 2.1. Figure 8 plots these core temperatures against measurements from the embedded thermocouple for each heating power. Figure 8 shows very good agreement between measurements based on the theoretical model and thermocouple measurements, with a peak deviation of $0.89{ }^{\circ} \mathrm{C}$, well within instrument measurement errors.

Figure 9 plots the measured core temperature rise as a function of heating power, for both free convection and forced convection cooling conditions described above. In both cases, experimental data lie close to linear fits shown in Figure 9 with $\mathrm{R}^{2}$ values of 0.9943 and 0.9970 respectively, which is expected since temperature rise is a linear function of heating power in the experimental conditions encountered here. The slope of experimental data is lower for the forced convection case, which is also expected, since the presence of cross flow reduces overall thermal resistance, leading to lower temperature rise for a specific power, and lower slope for the relationship between the two. 
Finally, a set of experiments are carried at fixed power of $2.2 \mathrm{~W}$, but with a number of air flow speeds. The circumferential variation of temperature rise around the outer surface of the cylinder is presented in Figure 10, which shows, as expected, that the temperature rise reduces as fan speed increases. The nature of the circumferential variation, however, remains the same in each case. Figure 11 summarizes the core temperature determined through the theoretical model against thermocouple measurements. Similar to previous data, there is very good agreement between the two, with a maximum error of $0.77^{\circ} \mathrm{C}$, showing the capability of the theoretical model to determine the core temperature of the test cell in a non-invasive fashion by utilizing the temperature distribution measured on the outside of the cell.

\subsection{Comparison of finite and infinite cylinder models}

Experimental data analysis discussed so far uses the infinite cylinder model, which is applicable when there are negligible temperature gradients in the axial direction. Figure 12 plots the measured outside temperature as a function of $z$ along the outside surface of the cell with $1.04 \mathrm{~W}$ heat generation and free convective cooling. This figure shows negligible axial variation in the outer temperature, which justifies the use of the infinite cylinder model for analyzing experimental data. In order to further examine the regime in which the finite cylinder model may be used, data analysis is carried out using the finite cylinder model on experimental data of the entire outer surface temperature measurement. Figure 13 plots the predicted core temperature from the finite cylinder model for a number of values of the convective heat transfer coefficients on the ends of the cylinder. Figure 13 shows that as the convective heat transfer coefficient becomes smaller and smaller, the core temperature prediction from the finite cylinder model approaches the thermocouple-measured core temperature, as well as the infinite cylinder model prediction. This is along expected lines, since the two ends of the test cell are insulated during 
experiments, and hence a small value of the convective heat transfer coefficient is expected. Further, theoretically, a small convective heat transfer at the ends, together with uniform heat generation suppresses axial thermal conduction, and makes thermal conduction in the cylinder almost exclusively radial in nature, thereby obviating the need for using the finite cylinder model.

In making the choice for whether the infinite or finite cylinder model is to be used for data analysis, it is recommended to examine the axial variation in the measured temperature distribution on the outside surface. If the variation is negligible, as is the case in these measurements, the infinite cylinder model would be sufficient.

\subsection{Uncertainty analysis}

This sub-section analyzes experimental uncertainty in the two key measurements reported here - measurement of the core temperature through the embedded thermocouple, and through the measurement method discussed here. Uncertainty in the thermocouple measurement is $1{ }^{\circ} \mathrm{C}$, based on manufacturer specifications. Uncertainty in the surface temperature based measurement method arises from three key parameters as shown in equation (16) - uncertainty in heat generation measurement, in thermal conductivity measurement, and in infrared-based outside temperature measurement. Since heat generation is determined using electrical measurements, the uncertainty is expected to be very low due to the high measurement accuracy of Keithley 2612A and Keithley 2100 instruments. As discussed in a recent paper [18], uncertainty in thermal conductivity measurement is estimated to be $\pm 5 \%$. Finally, uncertainty in infrared-based outside temperature measurement is expected to be $0.92{ }^{\circ} \mathrm{C}$, based on infrared calibration 
described in section 4.1 and Figure 4. As a result, based on error propagation in equation (16), the overall uncertainty in the core temperature measurement from the method described in this paper is estimated to be $\pm 10 \%$, arising mostly due to uncertainty in thermal conductivity measurement and infrared-based temperature measurements. The agreement between the method described in this paper, and embedded thermocouple measurement is within the experimental measurement uncertainty.

\section{Conclusions}

Non-invasive measurement of temperature inside solid bodies is of significant importance for a wide variety of engineering applications where the body temperature governs performance and reliability. The theoretical model and experimental data presented in the paper establish a novel technique for measuring the inside core temperature of a solid body in steady state using measurements of the outside temperature distribution on the outside of the body. While the results discussed here apply to steady state, an extension to core temperature measurement in transient conditions may be an important future work. The method discussed here can be easily extended to solids of other shapes as long as the thermal conduction problem within the solid could be solved to derive a relationship between the core and outside temperatures, similar to the theoretical treatment described in this paper. These results validate a novel metrology method for temperature measurement inside solid bodies, which may contribute towards thermal design and optimization of a wide variety of engineering systems.

\section{ACKNOWLEDGMENTS}

This material is based upon work supported by the National Science Foundation under NSF CAREER Grant No. CBET-1554183. Financial support from Office of Naval Research 
through DURIP Award \# N00014-14-1-0752 for acquisition of infrared camera is also gratefully acknowledged.

\section{REFERENCES}

[1] J. Goodenough, K.-S. Park, The Li-ion rechargeable battery: a perspective, J. Am. Chem. Soc., 135, 2013, pp. 1167-1176.

[2] B. Scrosati, J. Garche, Lithium batteries: Status, prospects and future, J. Power Sources, 9, 2010, pp. 2419-2430.

[3] K. Shah, S.J. Drake, D.A. Wetz, J. K. Ostanek, S.P. Miller, J.M. Heinzel, A. Jain, Modeling of steady-state convective cooling of cylindrical Li-ion cells, J. Power Sources, 258, 2014, pp. 374-381.

[4] K. Shah, S.J. Drake, D.A. Wetz, J.K. Ostanek, S.P. Miller, J.M. Heinzel, A. Jain, An experimentally validated transient thermal model for cylindrical Li-ion cells, J. Power Sources, 271, 2014, pp. 262-268.

[5] D. Lisbona, T. Snee, A review of hazards associated with primary Lithium and Lithium-ion batteries, Process Safety \& Env. Protection, 89, 2011, pp. 434-442.

[6] L. Michalski, K. Eckersdorf, J. Kucharski, J. McGhee, Temperature Measurement, $2^{\text {nd }}$ Edition, Wiley, 2001, ISBN: 978-0-471-86779-1.

[7] D.T. McGee, Principles and Methods of Temperature Measurement, John Wiley \& Sons, 1988, ISBN: 0-471-62767-4.

[8] P.R.N. Childs., J.R. Greenwood, C.A. Long, Review of temperature measurement, Rev. Scientific Instruments, 71 (8), 2000, pp. 2959-2978.

[9] P.E. Raad, P.L. Komarov, M.A. Bettiati, Thermoreflectance temperature measurements for optically emitting devices, Microelectronics J., 45, 2014, pp. 515-520. 
[10] J.J.L. Franco, E. Boemo, E. Castillo, L. Parrilla, Ring oscillators as thermal sensors in FPGAs: Experiments in low voltage, In: Proc. VI Southern Programmable Logic Conf., 2010, pp. $133-137$.

[11] T.E. Cooper, R.J. Field, J.F. Meyer, Liquid crystal thermography and its application to study of convective heat transfer, ASME J. Heat Transfer, 97(3), 1975, pp. 442-450.

[12] D.P. DeWiit, G.D. Nutter, Theory and Practice of Radiation Thermometry, $1^{\text {st }}$ Edition, John Wiley \& Sons, 1988, ISBN: 0-471-61018-6.

[13] Thermophysical Properties of Materials For Nuclear Engineering: A Tutorial and Collection of Data, International Atomic Energy Agency (IAEA), 2008. Available at http://wwwpub.iaea.org/MTCD/publications/PDF/IAEA-THPH_web.pdf, accessed Feb 26, 2016.

[14] H. Yapici, O. Ipek, V. Ozceyhan, Temperature distribution in nuclear fuel rod and variation of the neutronic performance parameters in (D-T) driven hybrid reactor system, Annals of Nuclear Energy, 28, 2001, pp. 1825-1850.

[15] C.R. Regis, R.M. Cotta, J. Su, Improved lumped analysis of transient heat conduction in a nuclear fuel rod, Int. Comm. Heat Mass Transfer, 27(3), 2000, pp. 357-366.

[16] D. Linden, T.B. Reddy, 'Handbook of Batteries,' 3rd Ed., McGraw-Hill, New York, 2002.

[17] S.J. Drake, M. Martin, D.A. Wetz, J.K. Ostanek, S.P. Miller, J.M. Heinzel, A. Jain, Heat generation rate measurement in a Li-ion cell at large C-rates through temperature and heat flux measurements, J. Power Sources, 285, 2015, pp. 266-273. [18] S.J. Drake, D.A. Wetz, J.K. Ostanek, S.P. Miller, J.M. Heinzel, A. Jain, Measurement of anisotropic thermophysical properties of cylindrical Li-ion cells, J. Power Sources, 252, 2014, pp. 298-304.

[19] V. Vishwakarma, C. Waghela, Z. Wei, R. Prasher, S.C. Nagpure, J. Li, F. Liu, C. Daniel, A. Jain, Heat transfer enhancement in a Lithium-ion cell through improved material-level thermal transport, J. Power Sources, 300, 2015, pp. 123-131.

[20] C. Forgez, D.V. Do, G. Friedrich, M. Morcotte, C. Delacourt, Thermal modeling of a cylindrical $\mathrm{LiFePO}_{4} /$ graphite lithium-ion battery, J. Power Sources, 195, 2010, pp. 2961-2968. 
[21] A. Abdul-Aziz, D.J. Roth, R. Cotton, G.F. Studor, E. Christiansen, P.C. Young, Material Characterization and Geometric Segmentation of a Composite Structure Using Microfocus XRay Computed Tomography Image-Based Finite Element Modeling, Journal of Materials Evaluation, 71(2), 2013, pp. 167-175.

[22] S. R. Stock, X-Ray Computed Tomography, Characterization of Materials, John Wiley \& Sons, Inc., 2012, pp. 1-18. DOI: 10.1002/0471266965.com131

[23] R. Zoughi, Microwave non-destructive testing and evaluation, $1^{\text {st }}$ Edition, Kluwer Academic Publishers, 2000, ISBN: 978-90-481-4015-2.

[24] T. Kundu, Ultrasonic nondestructive evaluation: engineering and biological material characterization, CRC Press, 2004. ISBN: 13-978-0-203-50196-2.

[25] P.J. Withers, H.K.D.H. Bhadeshia, Residual stress. Part 1 - Measurement techniques, Materials Sci. \& Technol., 17(4), pp. 355-365.

[26] M. Takahashi, I. Ihara., Ultrasonic determination of temperature distribution in thick plates during single sided heating, Mod. Phys. Lett. B 22 (11), 2008, 971.

[27] I. Ihara, T. Tomomatsu, In-situ measurement of internal temperature distribution of sintered materials using ultrasonic technique, Materials Science and Engineering, 18, 2011.

[28] H.N.G. Wadley, S.J. Norton, F. Mauer, B. Droney, Ultrasonic measurement of internal temperature distribution, Phil. Trans. R. Soc. Lond. A, 320, 1986, pp. 341-361.

[29] S.J. Norton, L.R. Testardi, H.N.G. Wadley, Reconstructing internal temperature distributions from ultrasonic time-of-flight tomography and dimensional resonance measurements, Ultrasonics Symposium, 1983, pp. 850-855.

[30] R.R. Richardson, P.T. Ireland, D.A. Howey, Battery internal temperature estimation by combined impedance and surface temperature measurement, Journal Power Sources, 265, 2014, pp. 254-261. 
[31] J.B. Robinson, J.A. Darr, D.S. Eastwood, G. Hinds, P.D. Lee, P.R. Shearing, O.O. Taiwo, D.J.L. Brett, Non-uniform temperature distribution in Li-ion batteries during discharge - A combined thermal imaging, X-ray micro-tomography and electrochemical impedance approach, Journal of Power Sources, 252, 2014, pp. 51-57.

[32] R. Srinivasan, B.G. Carkhuff, M.H. Butler, A.C. Baisden, Instantaneous measurement of the internal temperature in lithium-ion rechargeable cells, Electrochimica Acta, 56, 2011, pp. 61986204.

[33] D. Sarkar, K. Shah, A. Haji-Sheikh, A. Jain, Analytical modeling of temperature distribution in an anisotropic cylinder with circumferentially-varying convective heat transfer, Int. J. Heat and Mass Transfer, 79, 2014, pp. 1027-1033.

[34] M.N. Özişik, Heat conduction, $2^{\text {nd }}$ Edition, John Wiley \& Sons, Inc., 1980, ISBN: 0-47105481-X.

[35] W.M. Kays, M.E. Crawford Convective Heat and Mass Transfer, McGraw-Hill, New York, 1993. 


\section{List of Figures:}

Figure 1: Schematic of the geometry of (a) infinite, and (b) finite cylinders analyzed in theoretical models for determining core temperature from outside temperature distribution measurements.

(NEW) Figure 2: (a) Picture and (b) Schematic of the thermal test cell for remote, non-invasive core temperature measurement in steady state.

(NEW) Figure 3: (a) Picture and (b) Schematic of the experimental test set up for remote, noninvasive core temperature measurement in steady state.

Figure 4: Plot of temperature measured by IR camera as a function of set stage temperature for four different surface and calibration conditions. Inset shows a picture of experimental setup.

Figure 5: Comparison of core temperature determined from infinite cylinder theoretical model and core temperature measured using thermocouple embedded in thermal test cell. Data are taken for a number of heating powers, ranging from $0.31 \mathrm{~W}$ to $2.2 \mathrm{~W}$, with free convection cooling conditions. Broken line shows the ideal $45^{\circ}$ line.

Figure 6: Circumferential variation in measured temperature on the outside of the cell in free and forced convection conditions. Data are non-dimensionalized based on peak temperature for each condition.

Figure 7: Circumferential variation in measured temperature on the outer surface of the cell in forced convection conditions for a number of heating powers.

Figure 8: Comparison of core temperature determined from infinite cylinder theoretical model and core temperature measured using thermocouple embedded in thermal test cell. Data are taken for a number of heating powers, ranging from $1.68 \mathrm{~W}$ to $3.43 \mathrm{~W}$, with forced convection cooling conditions. Broken line shows the ideal $45^{\circ}$ line.

Figure 9: Plot of measured core temperature as a function of heating power for both free and forced convection cooling conditions. A linear fit is also shown for each data set.

Figure 10: Circumferential variation in temperature in forced convection cooling condition for a number of air flow speeds. 
Figure 11: Comparison of core temperature determined from theoretical model with thermocouple measurements of forced convection cooling at a number of air flow speeds ranging from 1.5 to $3.5 \mathrm{~m} / \mathrm{s}$.

Figure 12: Measured outside surface temperature as a function of $\mathrm{z}$ for free convection cooling conditions at $1.04 \mathrm{~W}$ power.

Figure 13: Comparison of core temperature predicted by the finite cylinder model for different values of the convective heat transfer coefficient with infinite cylinder model for 1.04 $\mathrm{W}$ heat generation and free convective cooling case. Corresponding thermocouple measurement of the core temperature is indicated on the y-axis. 
(a)

(b)

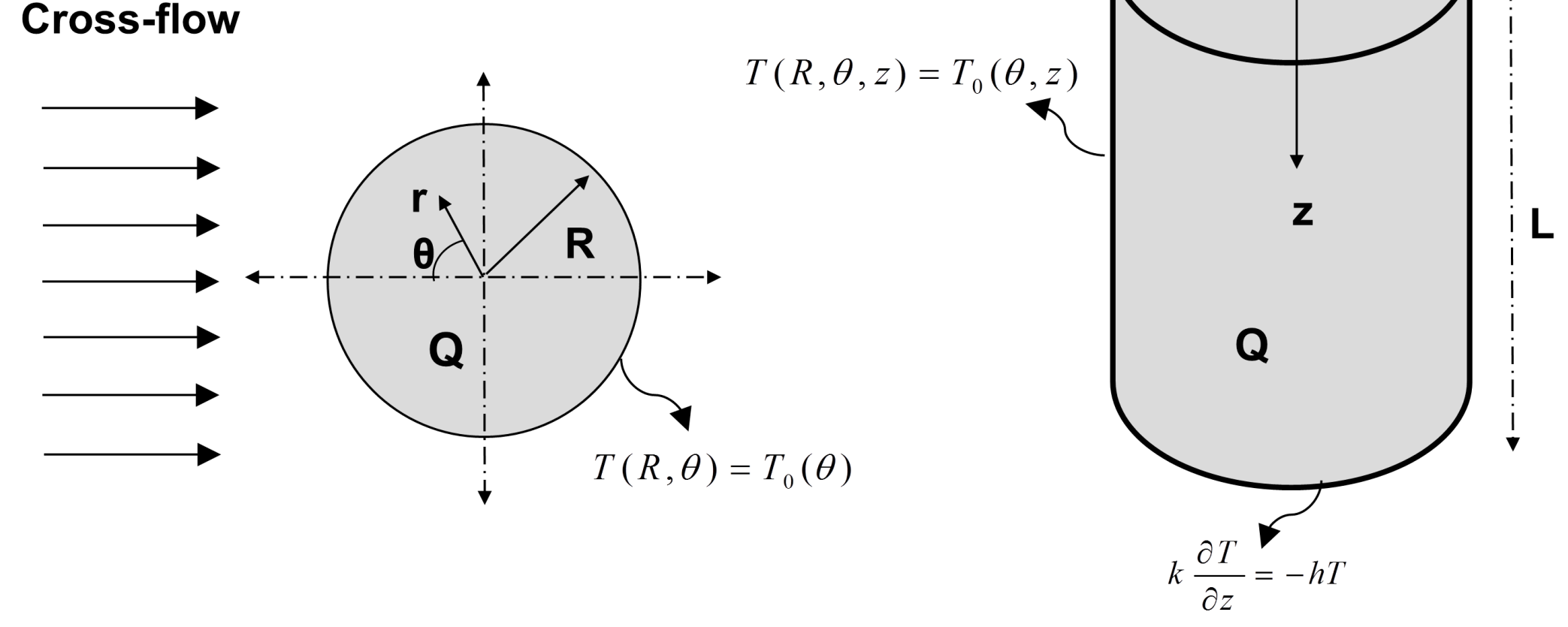

Figure 1: Schematic of the geometry of (a) infinite, and (b) finite cylinders analyzed in theoretical models for determining core temperature from outside temperature distribution measurements. 
(a)

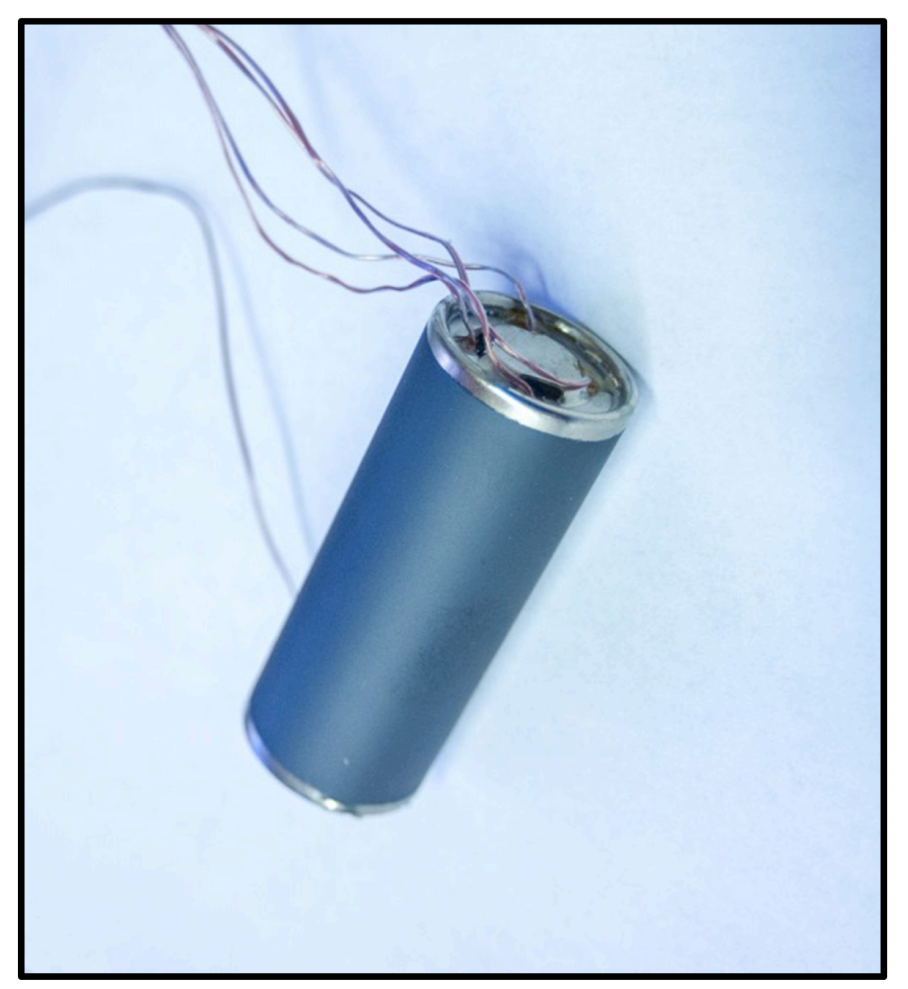

(b)

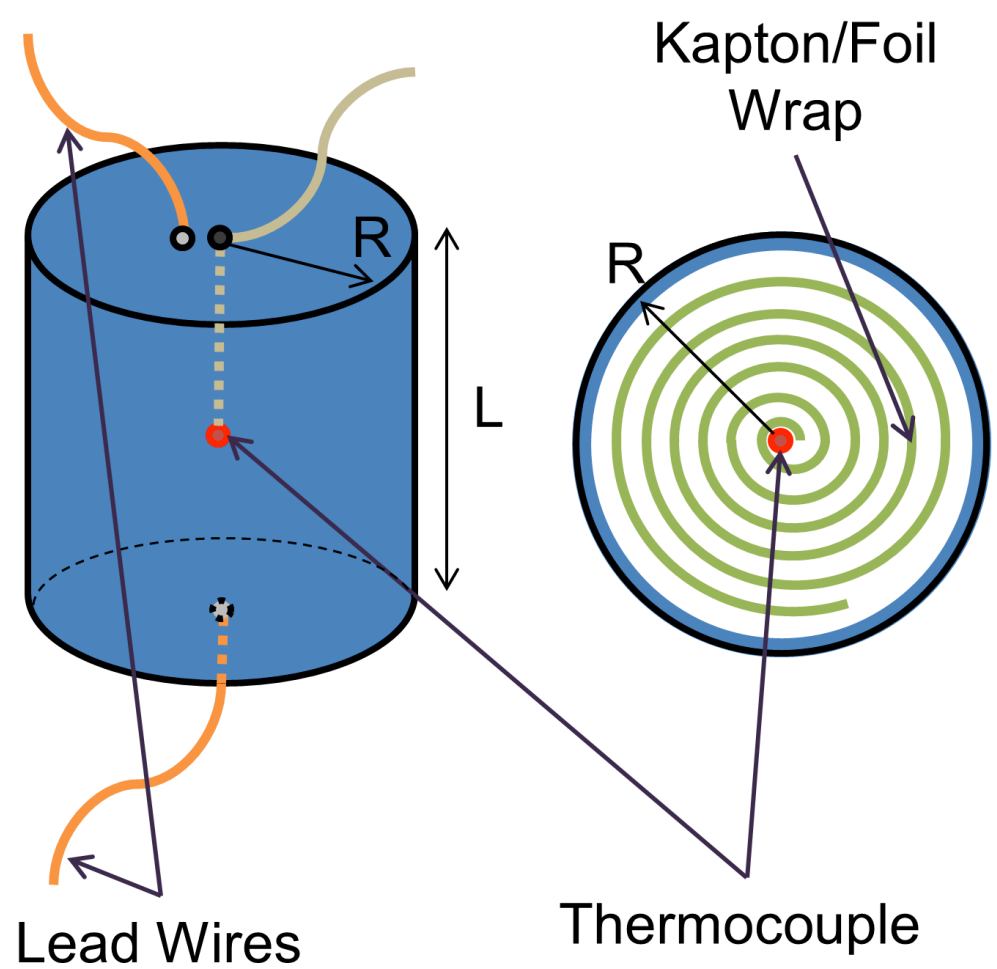

Figure 2: (a) Picture and (b) Schematic of the thermal test cell for remote, non-invasive core temperature measurement in steady state. 
(a)

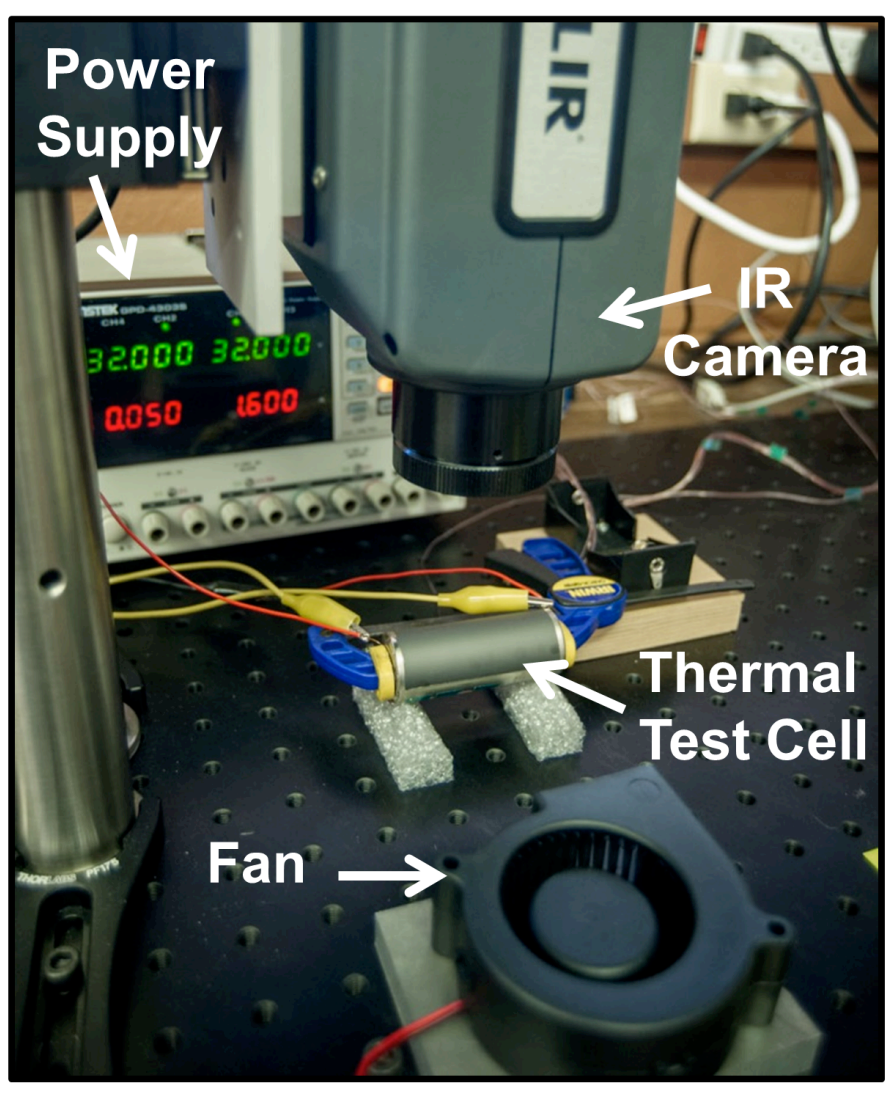

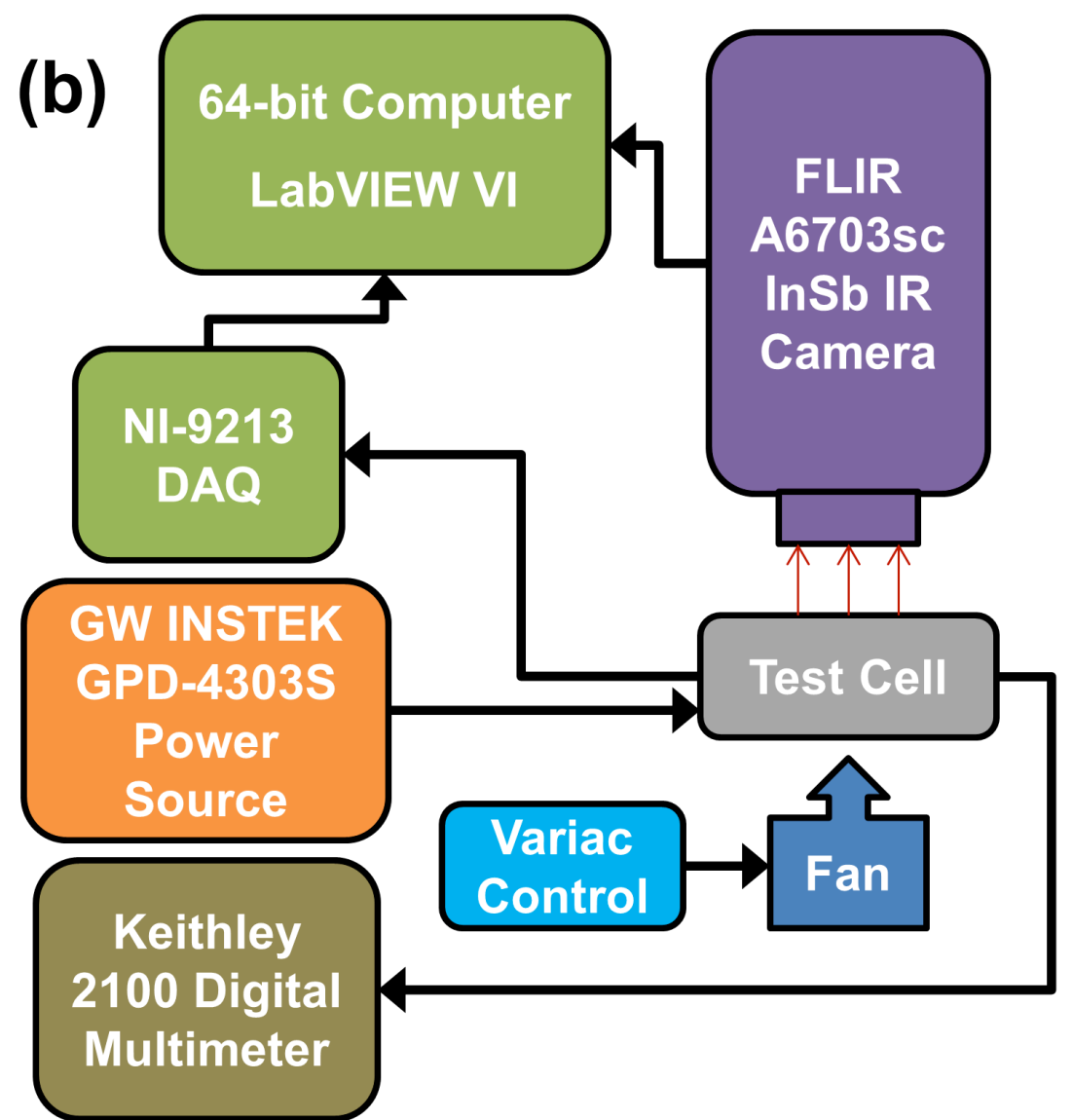

Figure 3: (a) Picture and (b) Schematic of the experimental test set up for remote, non-invasive core temperature measurement in steady state. 


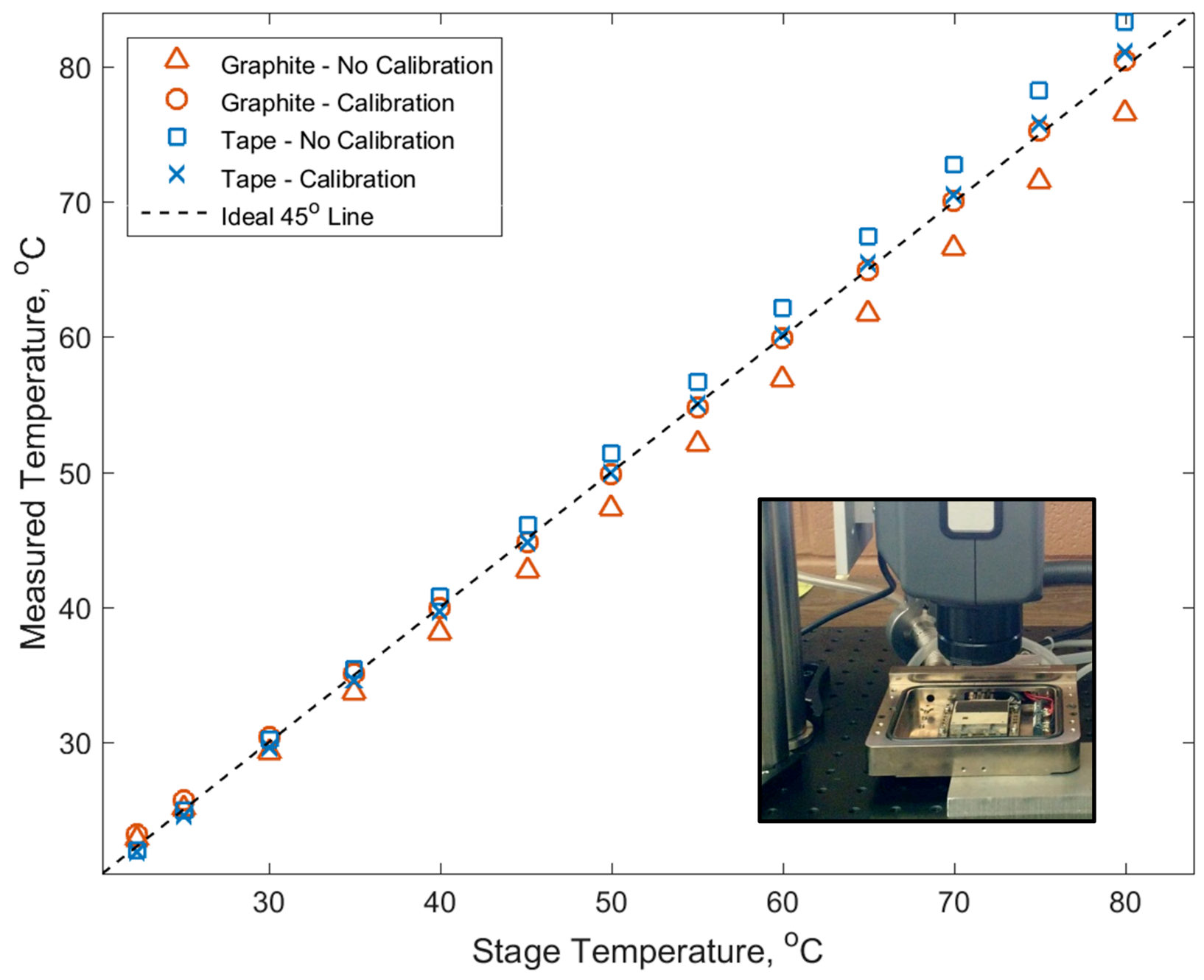

Figure 4: Plot of temperature measured by IR camera as a function of set stage temperature for four different surface and calibration conditions. Inset shows a picture of experimental setup. 


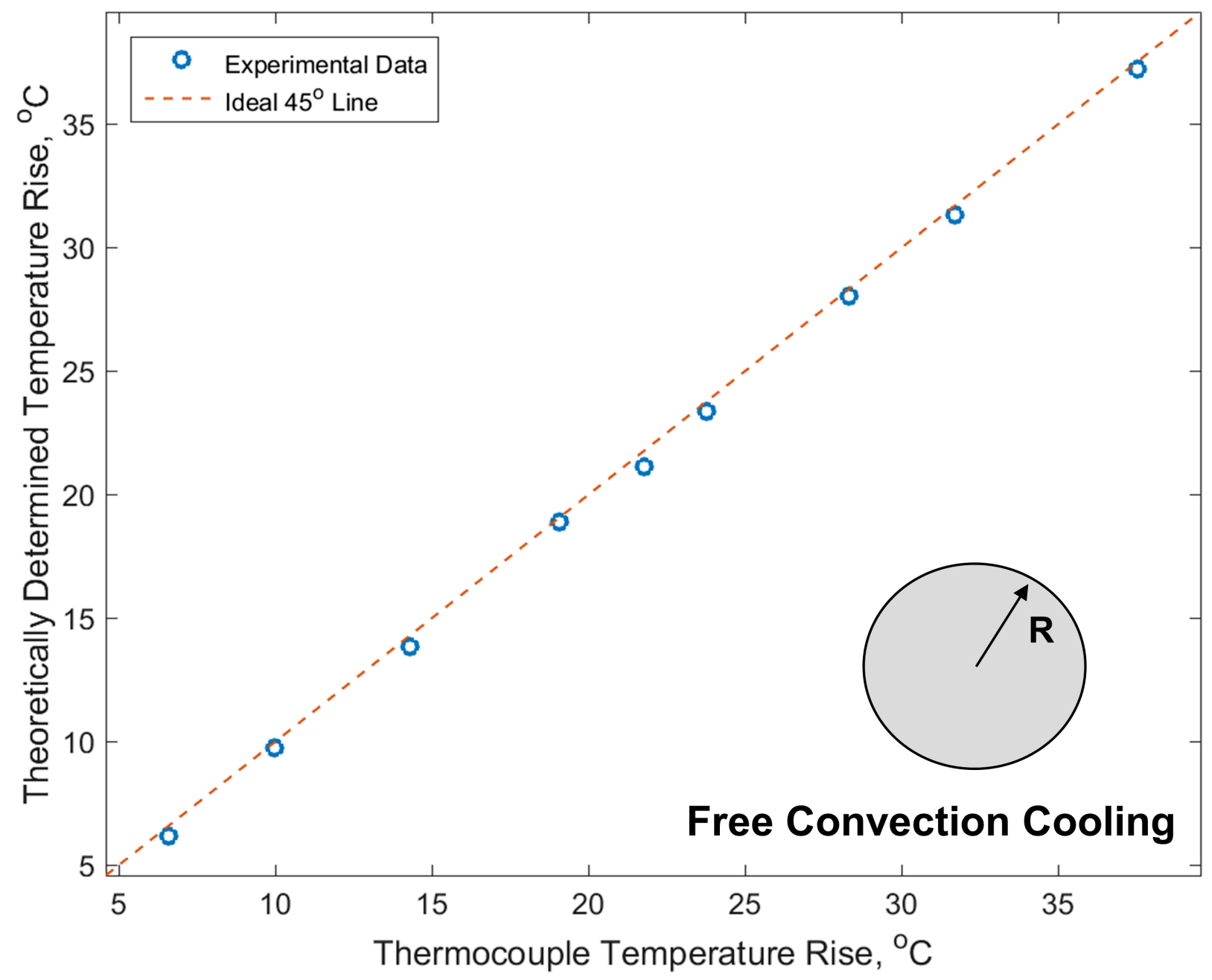

Figure 5: Comparison of core temperature determined from infinite cylinder theoretical model and core temperature measured using thermocouple embedded in thermal test cell. Data are taken for a number of heating powers, ranging from $0.31 \mathrm{~W}$ to $2.2 \mathrm{~W}$, with free convection cooling conditions. Broken line shows the ideal $45^{\circ}$ line. 


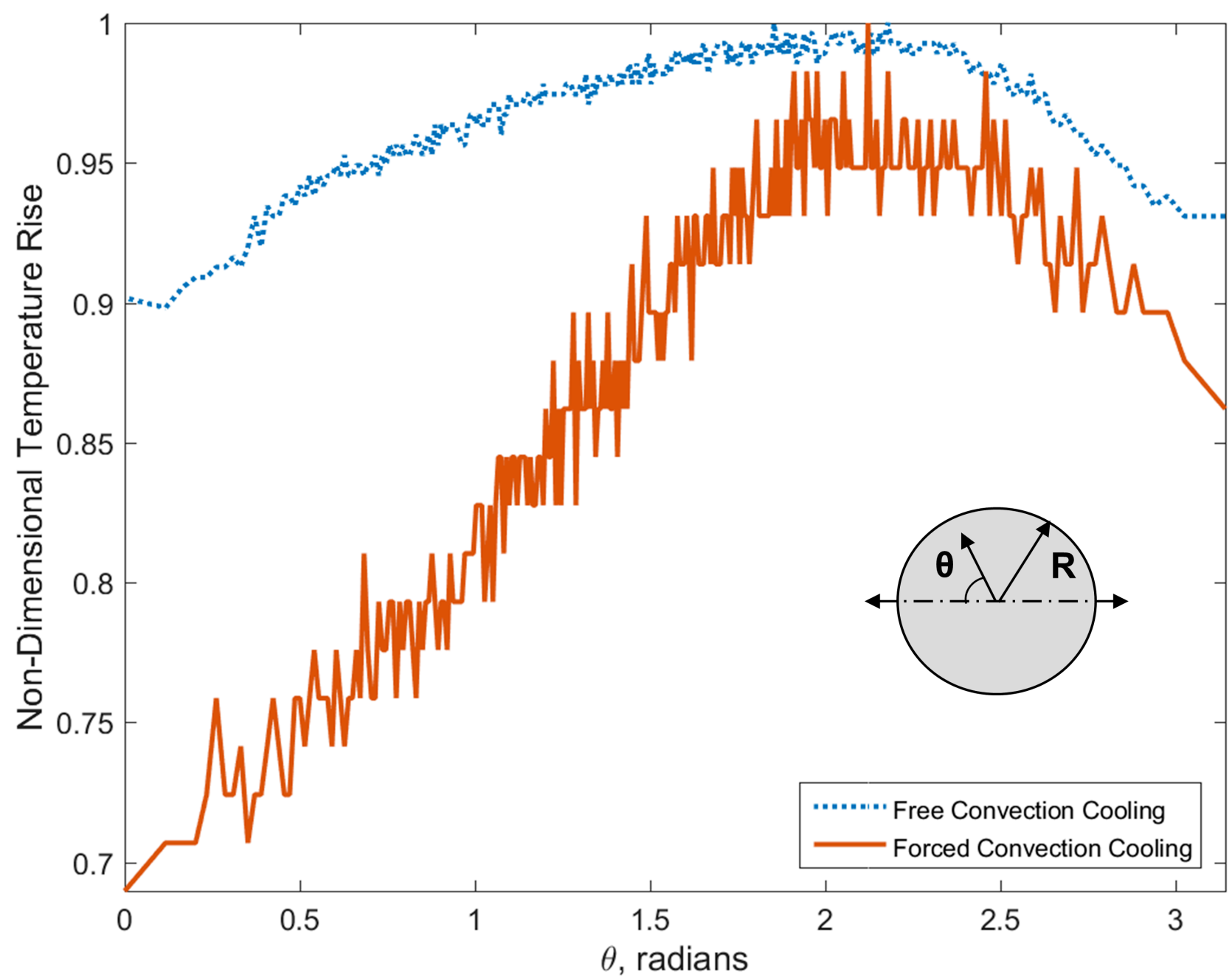

Figure 6: Circumferential variation in measured temperature on the outside of the cell in free and forced convection conditions. Data are non-dimensionalized based on peak temperature for each condition. 


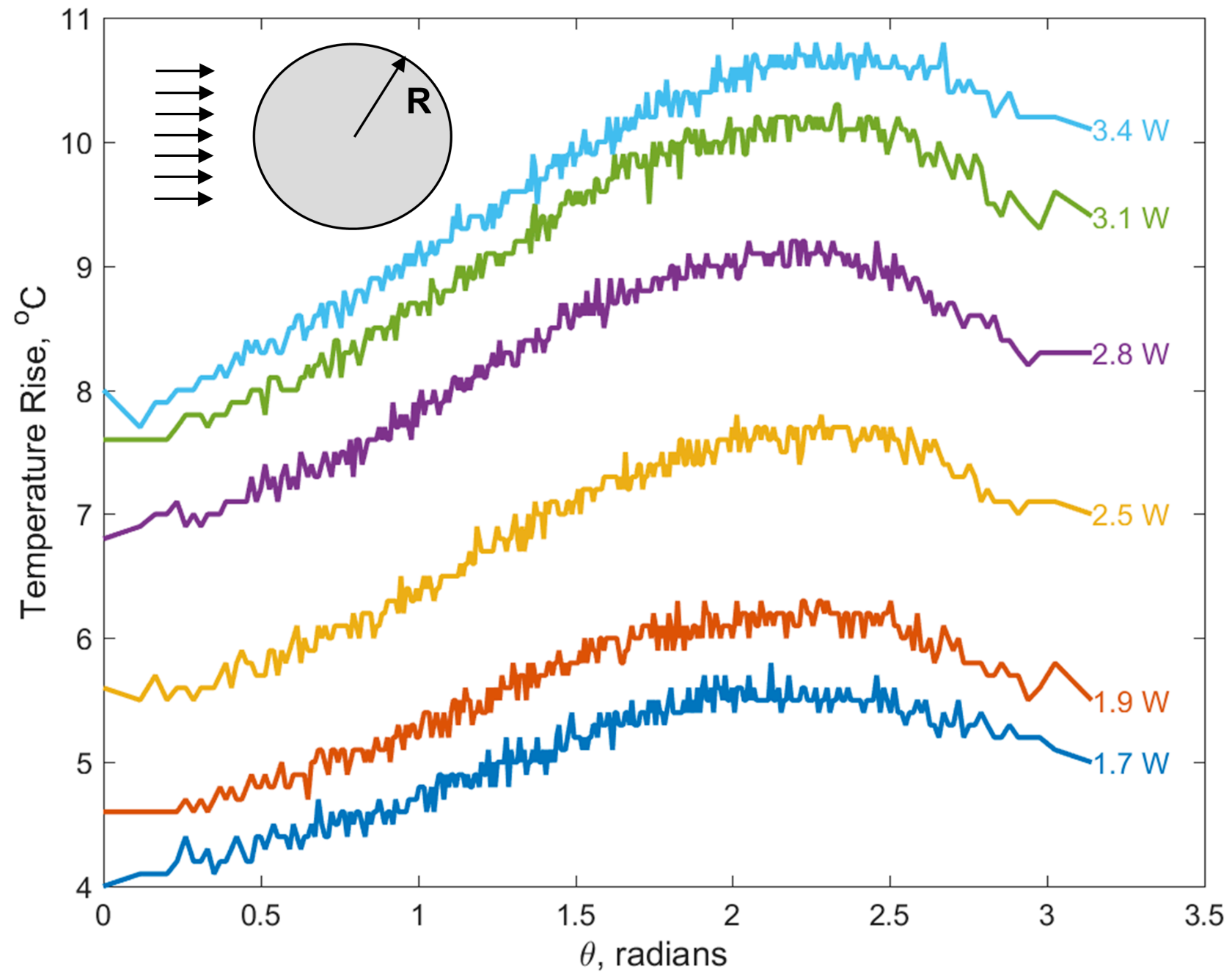

Figure 7: Circumferential variation in measured temperature on the outer surface of the cell in forced convection conditions for a number of heating powers. 


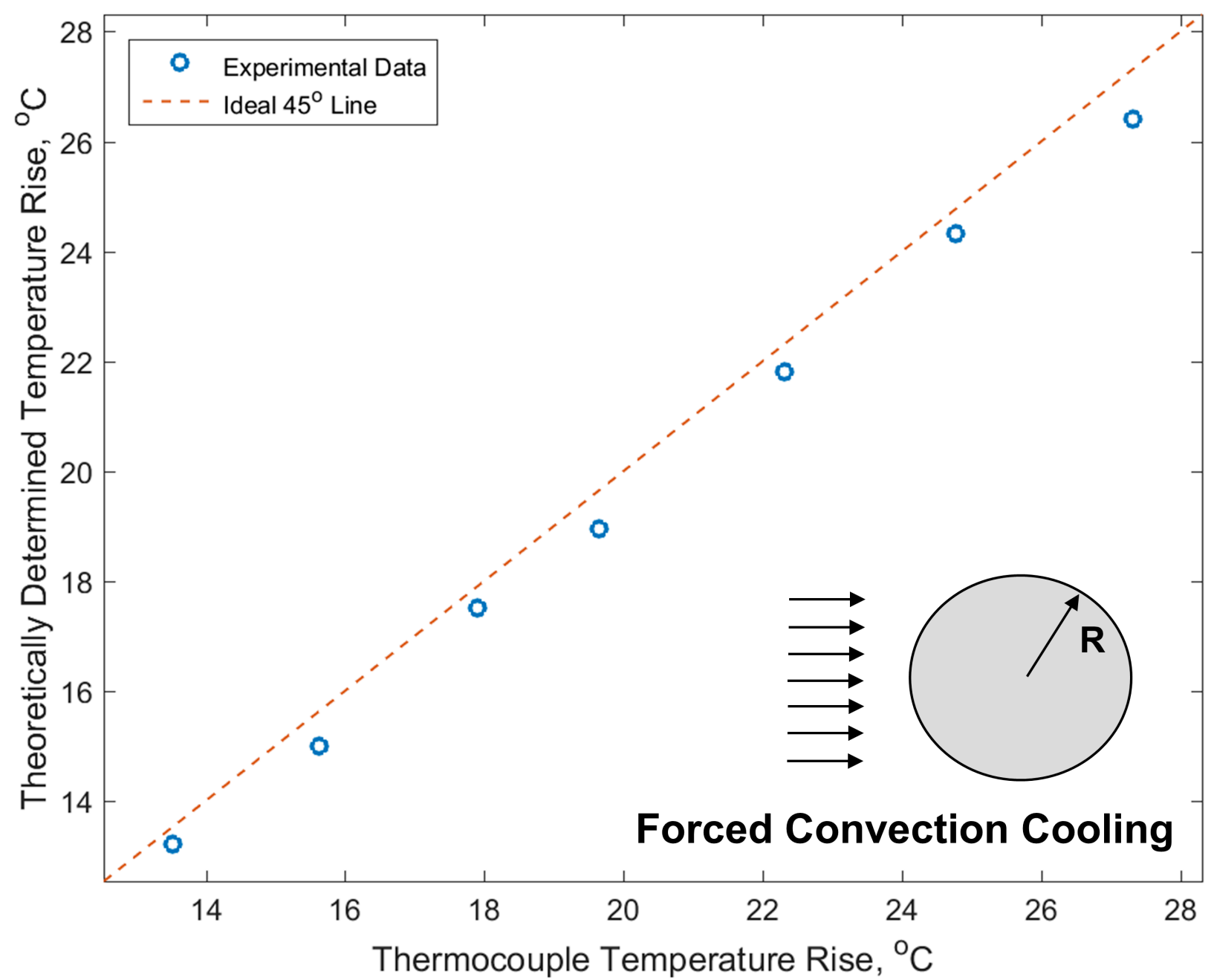

Figure 8: Comparison of core temperature determined from infinite cylinder theoretical model and core temperature measured using thermocouple embedded in thermal test cell. Data are taken for a number of heating powers, ranging from $1.68 \mathrm{~W}$ to $3.43 \mathrm{~W}$, with forced convection cooling conditions. Broken line shows the ideal $45^{\circ}$ line. 


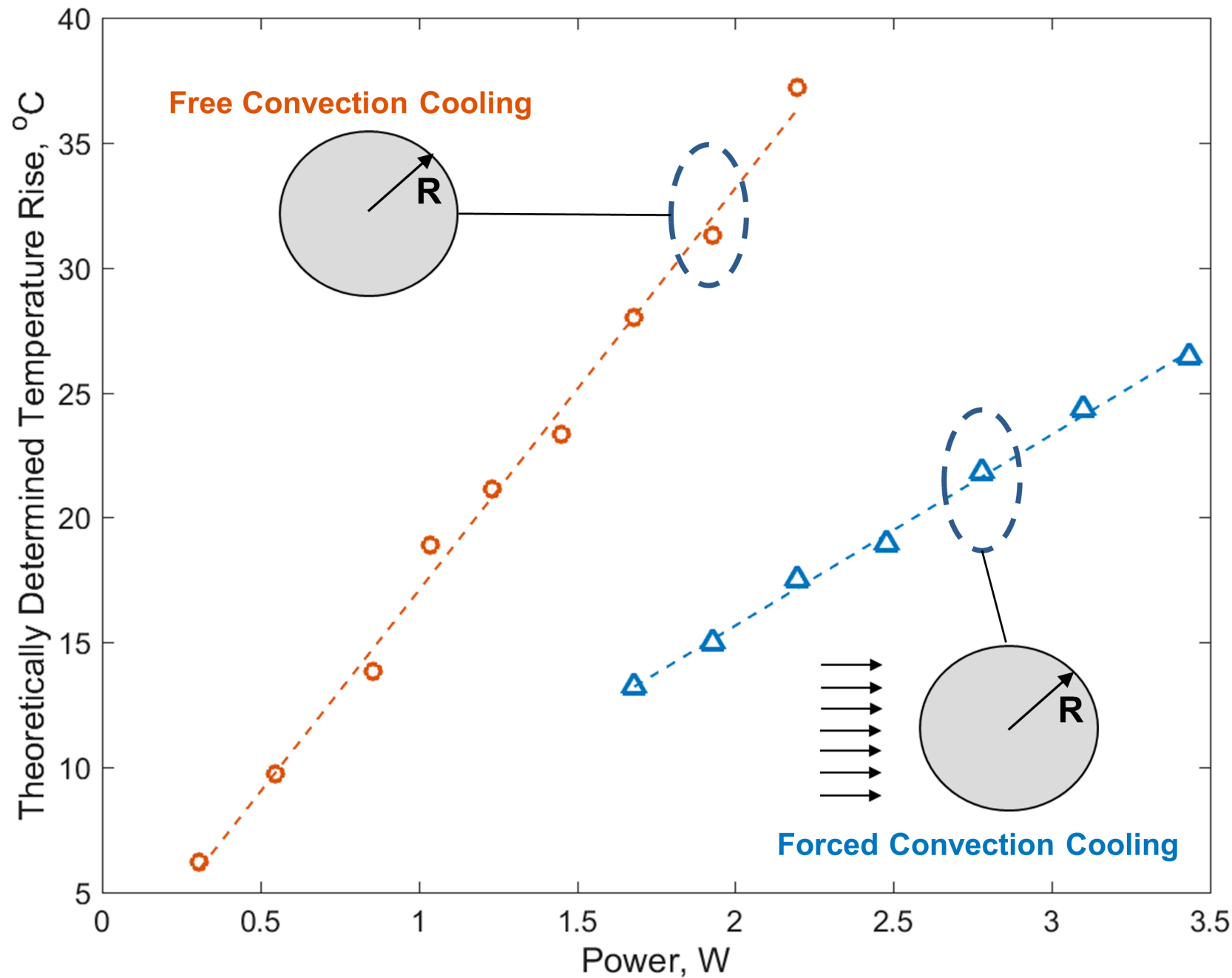

Figure 9: Plot of measured core temperature as a function of heating power for both free and forced convection cooling conditions. A linear fit is also shown for each data set. 


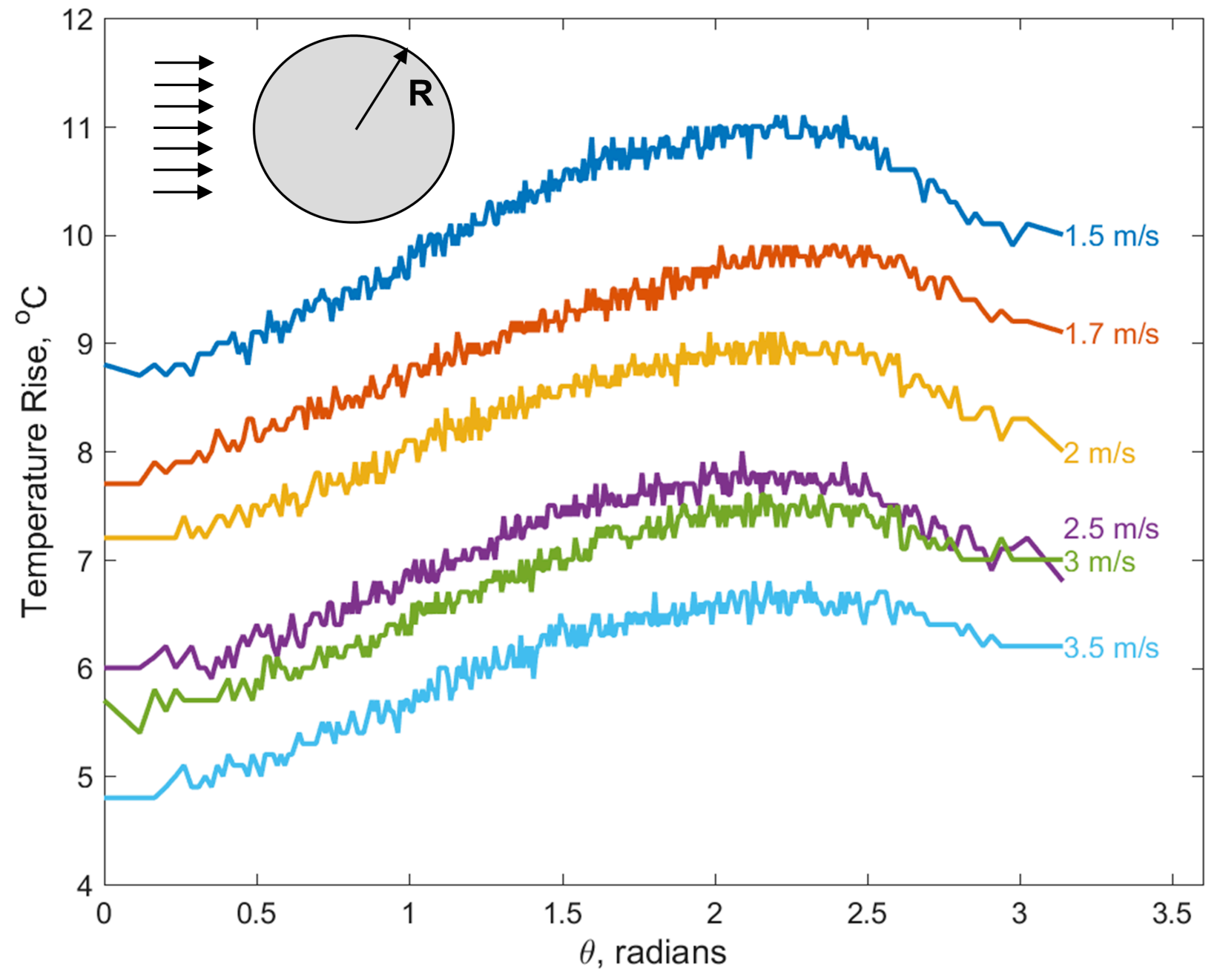

Figure 10: Circumferential variation in temperature in forced convection cooling condition for a number of air flow speeds. 


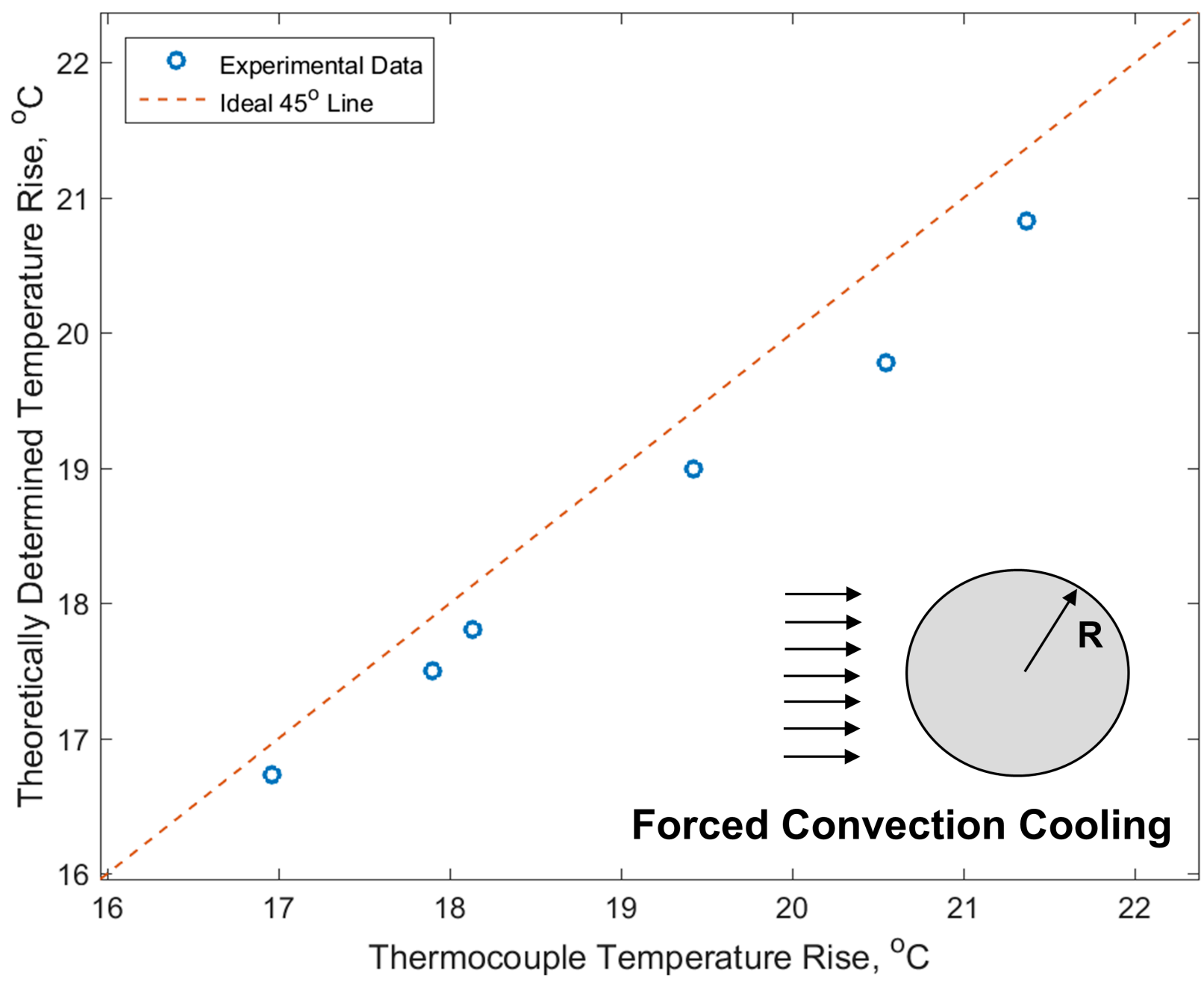

Figure 11: Comparison of core temperature determined from theoretical model with thermocouple measurements of forced convection cooling at a number of air flow speeds ranging from 1.5 to $3.5 \mathrm{~m} / \mathrm{s}$. 


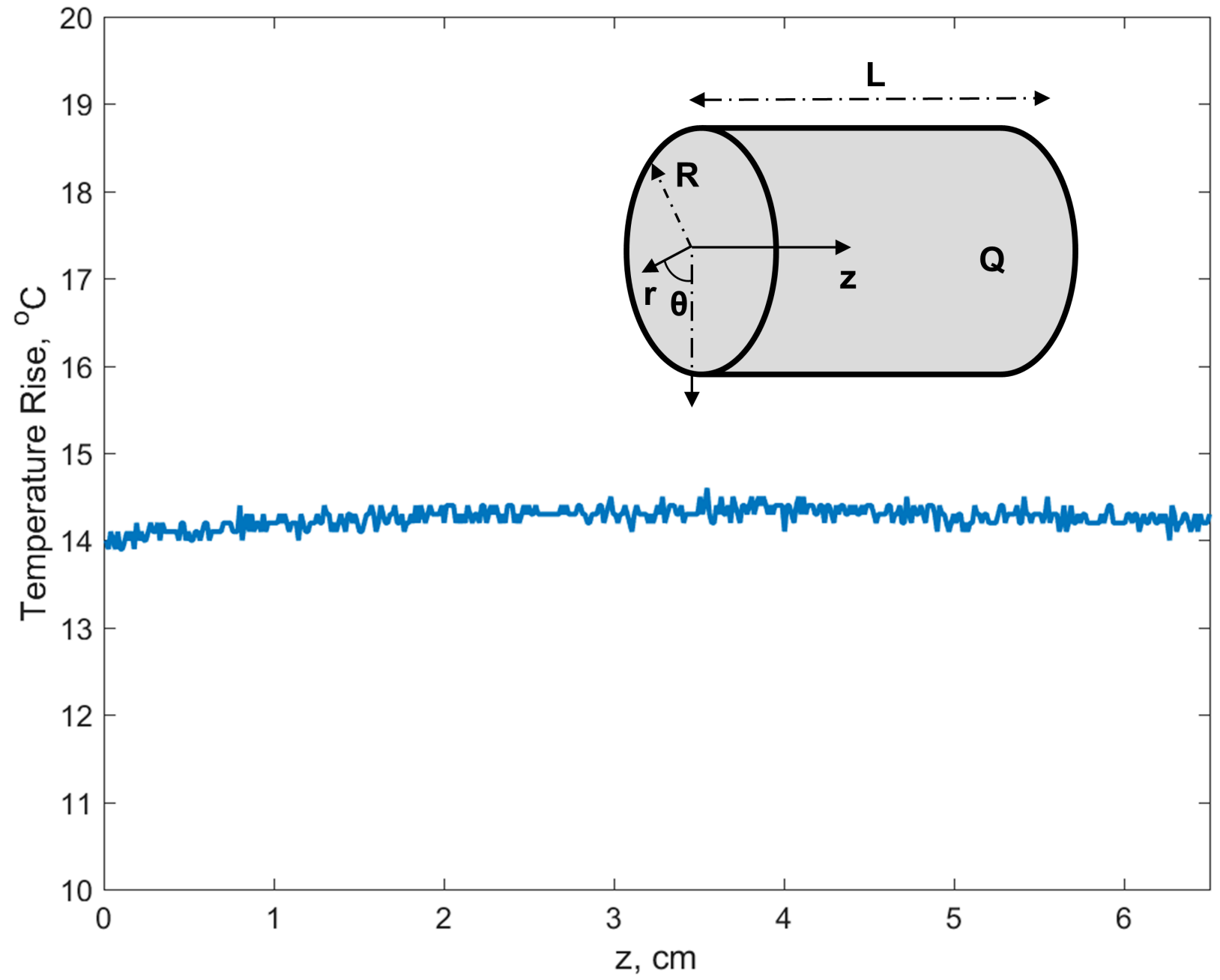

Figure 12: Measured outside surface temperature as a function of $\mathrm{z}$ for free convection cooling conditions at $1.04 \mathrm{~W}$ power. 


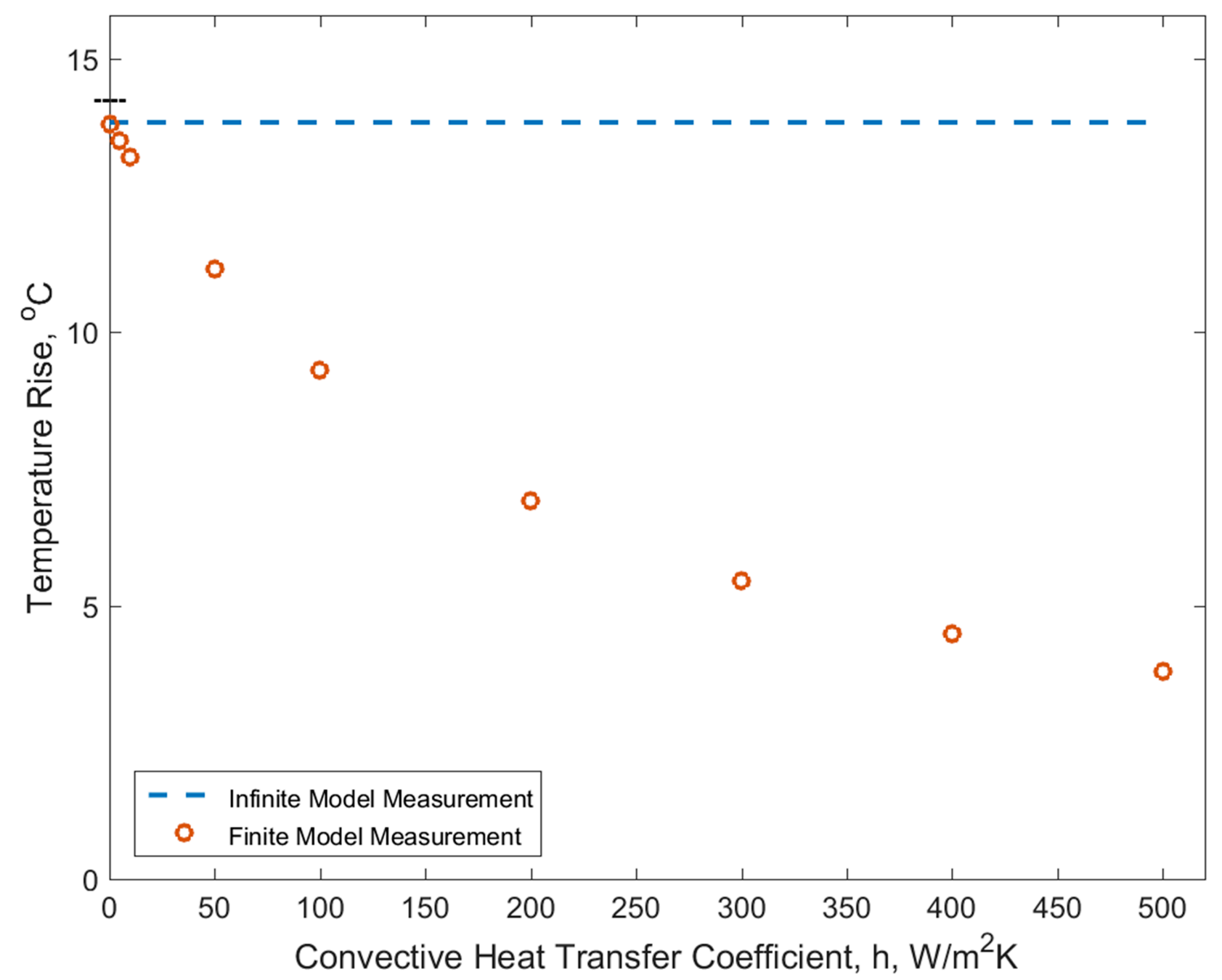

Figure 13: Comparison of core temperature predicted by the finite cylinder model for different values of the convective heat transfer coefficient with infinite cylinder model for $1.04 \mathrm{~W}$ heat generation and free convective cooling case. Corresponding thermocouple measurement of the core temperature is indicated on the y-axis. 